\title{
FAKTOR-FAKTOR EKOLOGIS YANG BERPENGARUH TERHADAP STRUKTUR POPULASI KUMBANG BADAK (Oryctes rhinoceros L. )
}

\author{
Desinta Dwi Nuriyanti ${ }^{\left.1^{*}\right)}$ Imam Widhiono ${ }^{2)}$ Agus Suyanto ${ }^{3)}$ \\ ${ }^{1,2}$ ) Fakultas Biologi Universitas Jenderal Soedirman \\ ${ }^{3}$ )Fakultas Pertanian Universitas Jenderal Soedirman \\ *email : desintadwi@yahoo.com
}

\begin{abstract}
Rhinoceros beetle (Oryctes rhinoceros L.) can live optimally with the support of a suitable ecological factors. Ecological factors which include habitat waste organic materials of vegetation, the natural enemies, the season, and the weather factors (such as:temperature, rainfalls, and humidity) were investigated by their effects on the population structure of the Rhinoceros beetle during October to December 2015.

This study is a survey of sampling which had been done four times, twice in the dry season and twice in the rainy season. The data were analyzed with multivariate analysis, whereas to determine the most ecological factors, it is needed a continued study by Duncan test.

The results of multivariate analysis of variance abundance of each stage of the rhinoceros beetle in some types of waste, season, temperature, habitat temperature, humidity, and moisture habitat and their interactions showed that the waste is a key ecological factor rhinoceros beetle larval development $(P<0.10)$.

The results of further analysis by Duncan test showed that the leaf litter waste is a key factor for larval development $(P<0.10)$, while the interaction of temperature and humidity habitat influence pupal stage $(P<0.20)$. Results of multivariate analysis also showed that interaction between the type of waste with humidity and moisture habitat; types of waste with humidity; humidity humidity habitat with a variety of factors that affect the interaction of the abundance of the rhinoceros beetle larvae stage $(P<0.10)$. The four factors that interact earlier showed important ecological factors that work together in influencing abundance rhinoceros beetle grub.

Unlike the grub abundance, pupa stage rhinoceros beetle abundance is determined by the interaction between the type of waste to the air temperature $(P<0.10)$, or in other words, the interaction between the type of waste to the air temperature is a key factor in the development of rhinoceros beetle pupa stage. Meanwhile, the interaction between temperature humidity habitat with habitat; temperature and humidity habitat habitat as the sole factor refers to the ecological factors that influence the development of rhinoceros beetle pupa stage.
\end{abstract}

Keywords: ecological factors, Oryctes rhinoceros L., population structure, habitat, season

\section{Pendahuluan}

Upaya pengendalian populasi kumbang badak telah banyak dilakukan, baik menggunakan cara mekanik, kimiawi maupun pengendalian hayati, namun demikan hasilnya masih belum memuaskan. Beberapa teknik pengendalian sudah dikembangkan untuk mengatasi serangan hama di lapangan tetapi masih terlalu mengandalkan peng- gunaan insektisida kimia sintetik. Hal ini sangat merugikan lingkungan hidup, membahayakan kesehatan manusia dan dapat meningkatkan biaya produksi. Kegagalan pengendalian populasi kumbang badak banyak disebabkan oleh kurang lengkapnya informasi ekologi yang mempengaruhi perkembangan populasi kumbang ini pada suatu tempat (Bedford, 2013). Dihellpan (1994) menemukan keberhasilan penggunaan Bacullovirus oryctes untuk mengendalikan kumbang 
badak sangat dipengaruhi kondisi lokal. Oleh karena itu untuk dapat menentukan metode dan strategi pengendalian hama kumbang badak yang tepat untuk diterapkan di perkebunan kelapa di Indonesia diperlukan informasi tentang faktor-faktor ekologis yang mempengaruhi perkembangan populasi hama kumbang badak. Namun demikian penelitian tentang tentang faktor-faktor ekologis yang mempengaruhi perkembangan populasi hama kumbang badak masih mengacu pada hasil penelitian di kawasan kepulauan Pasifik. Sehingga

\section{Metode}

a. Lokasi dan waktu

Penelitian dilakukan 4 Desa di Kecamatan Kutasari, Kabupaten Purbalingga, yaitu Desa Meri (limbah jerami) dengan titik koordinat $\pm 7^{\circ} 20^{\prime} 16$ "S 109'18'24"T, Desa Karangreja (batang pohon) dengan titik koordinat $\pm 7^{\circ} 21^{\prime} 04^{\prime \prime S}$ 109 18'42"T, Desa Karangaren (serasah daun) dengan titik koordinat $\pm 7^{\circ} 21^{\prime} 19^{\prime \prime} S$ 109'18'03"T, dan Desa Karangcegak untuk daerah tropis seperti di Jawa penelitian ini merupakan hal yang belum pernah dilakukan.

Penelitian ini bertujuan mengevaluasi faktor-faktor ekologis yang berpengaruh terhadap struktur populasi kumbang badak, menentukan faktor ekologis kunci yang paling berpengaruh terhadap struktur populasi kumbang badak, serta menentukan preferensi lokasi yang paling dipilih sebagai tempat perkembangbiakan yang cocok bagi kumbang badak.

(tanpa limbah) dengan titik koordinat \pm 7¹9'33"S 109¹7'56"T.

\section{b. Metode sampling}

Penelitian ini menggunakan metode suvey. Pengambilan sampel dilakukan sebanyak 4 kali,yaitu 2 kali pada musim kemarau dan 2 kali pada musim penghujan. Jumlah sampel yang diambil sebanyak $10 \%$ dari total populasi kelapa yang terserang kumbang badak.

Tabel 1. Rincian Serangan Kumbang Badak per Desa

\begin{tabular}{lcccc}
\hline Nama Desa & $\begin{array}{c}\text { Luas Wilayah } \\
\text { (ha) }\end{array}$ & $\begin{array}{c}\text { Jumlah Pohon } \\
\text { Kelapa }\end{array}$ & $\begin{array}{c}\text { Jumlah Kelapa } \\
\text { yang Terserang } \\
\text { Kumbang Badak }\end{array}$ & $\begin{array}{c}\text { Persentase } \\
(\%)\end{array}$ \\
\hline Meri & 168,50 & 2524 & 112 & 4,44 \\
Karangreja & 272,321 & 5850 & 600 & 10,26 \\
Karangaren & 72,6 & 178 & 106 & 59,55 \\
Karangcegak & 434,03 & 1521 & 102 & 6,71 \\
\hline
\end{tabular}

Pengambilan sampel dilakukan dengan 2 cara, yaitu dengan jala kabut, dan menggunakan feromontrap. Pada setiap pengambilan sampel dilakukan juga pengukuran faktor ekologis berupa suhu udara, suhu habitat, kelembaban udara, kelembaban habitat, dan curah hujan harian tertampung sebagai

\section{Hasil dan Pembahasan}

Hasil penelitian menunjukkan bahwa jumlah individu kumbang badak yang ditemukan pada keempat tipe parameter musim. Selain itu, saat pengambilan sampel juga diikuti pengamatan gejala rusak atau matinya sampel karena musuh alami.

c. Analisis data

Data selanjutnya diuji menggunakan analisis variansi multivariat dan dianalisis uji lanjut menggunakan Duncan.

habitat di kedua musim adalah sebanyak 2.472 ekor. Meskipun demikian, saat penelitian tidak ditemukan fase telur. Hal ini dikarenakan fase telur pada kumbang 
badak berlangsung hanya dalam 8-12 hari (Susantoet al, 2011), sehingga dimungkinkan pada saat sampling di lapangan siklus hidup kumbang badak sudah masuk pada tahap selanjutnya yaitu larva. Giblin-Davis (2001) mengemukakan bahwa telur kumbang badak akan menetas setelah 12 hari. Penelitian berlangsung selama 4 bulan sedangkan siklus kumbang badak berlangsung 4-9 bulan (Giblin-Davis, 2001). Dengan demikian penelitian yang dilakukan memotong siklus hidup kumbang badak, sehingga menjadi salah satu faktor tidak utuhnya siklus (tidak semua stadium diperoleh selama penelitian).

Hasil analisis variansi multivariat kelimpahan tiap stadium kumbang badak pada beberapa jenis limbah, musim, suhu udara, suhu habitat, kelembaban udara, dan kelembaban habitat serta interaksinya menunjukkan bahwa limbah merupakan faktor ekologis kunci perkembangan larva kumbang badak $(P<0,10$;

Hasil analisis uji lanjut dengan Duncan menunjukkan bahwa limbah serasah daun merupakan faktor kunci bagi perkembangan larva $(P<0,10$; $)$, sedangkan interaksi suhu dan kelembaban habitat mepengaruhi stadium pupa $(P<0,20$;).

Larva kumbang badak lebih memilih serasah daun karena serasah daun memiliki kandungan gizi yang lebih komplek bagi kumbang badak Limbah biomassa ini selanjutnya dimanfaatkan oleh mikroorganisme, cacing, dan hewanhewan kecil lain di dalam tanah sehingga terurai lagi menjadi unsur-unsur seperti nitrogen, fosfor, kalium, serta unsur mikro lainnya yang siap menjadi unsur hara bagi tanaman. Serasah daun menurut Ayuningtyas (2009) memiliki kandungan Karbon sebanyak 52,8\% dan Nitrogen sebanyak 1,24\%. Tingginya kandungan karbon pada serasah daun juga dikemukakan oleh Zulkifli et al. (2010). Tingginya kandungan $\mathrm{N}, \mathrm{P}$,dan $\mathrm{K}$ pada serasah daun dengan komposisi daun yang lebih komplek juga lebih tinggi dibanding jerami (Supriyadi, 2008).Kandungan mineral yang lebih kompleks menjadi alasan kuat serasah daun menjadi limbah yang paling paling disukai larva kumbang badak.

Hasil analisis multivariate juga menunjukkan bahwa interaksi antara jenis limbah dengan kelembaban udara dan kelembaban habitat; jenis limbah dengan kelembaban udara; kelembaban habitat dengan kelembaban udara merupakan berbagai faktor interaksi yang mempengaruhi kelimpahan stadium larva kumbang badak $(P<0,10)$. Ke empat faktor yang berinteraksi tadi menunjukkan faktor-faktor ekologis penting yang bekerja bersama-sama dalam mempengaruhi kelimpahan stadium larva kumbang badak.

Kelembaban udara yang rendah pada musim penghujan menyebabkan kelembaban habitat limbah menjadi cenderung basah. Larva yang berhabitat di limbah tersebut sangat cocok dengan habitat limbah yang basah. Kelembaban optimal larva untuk dapat berkembang dengan baik adalah 85\%-95\% (Siahaya, 2014). Sejalan dengan hal terseebut, Riostone (2010) juga mengemukakan bahwa larva tertarik pada kelembaban yang rendah (85-95\%) daripada kelembaban tinggi. Menurut Kamarudin et al (2005), populasi serangga kadangkadang berubah-ubah pada awal musim, terutama oleh faktor lingkungan yang mendukung seperti curah hujan, temperatur, dan kelembaban. Coleoptera dan serangga lainnya akan melimpah setelah hujan. Kumbang badak termasuk golongan Coleoptera yang berdasarkan hasil penelitian di lapangan jumlahnya juga meningkat di musim penghujan. Limbah sebagai habitat larva sangat dipengaruhi oleh kelembaban. Sebagaimana dikemukakan oleh Wesi (2014) bahwa ketersediaan nutrisi dan kelembaban mempengaruhi kepadatan populasi kumbang badak. Selain itu, kelembaban yang cenderung basah menurut Setyorini et al. (2006) juga mempengaruhi laju dekomposisi limbah organik karena mikroorganisme membutuhkan kadar air yang optimal untuk menguraikan material organik agar dapat menjadi sumber nutrisi.

Berbeda dengan keljmpahan larva, kelimpahan stadium pupa kumbang badak sangat ditentukan oleh interaksi 
antara jenis limbah dengan temperatur udara $(P<0,10$; tabel 4.1$)$ atau dengan perkataan lain, interaksi antara jenis limbah dengan temperatur udara merupakan faktor kunci perkembangan stadium pupa kumbang badak. Sedangkan, interaksi antara temperatur habitat dengan kelembaban habitat; temperatur habitat dan kelembaban habitat sebagai faktor tunggal menunjuk pada faktor ekologis yang mempengaruhi perkembangan stadium pupa kumbang badak.

Temperatur udara yang optimal akan berpengaruh pada dekomposisi limbah secara tidak langsung. Hal ini menyebabkan limbah menjadi terdekomposisi lebih sempurna. Menurut Supriyadi (2008), temperatur berpengaruh pada kecepatan dekomposisi bahan organik. Menurut, Rahayuwati et al. (2002), Kokon pupa kumbang badak terbuat dari serat-serat tandan kosong yang dijalin menjadi lonjong dan biasanya dijumpai pada tandan kosong yang sudah terdekomposisi sempurna. Sebagaimana dikemukakan pula oleh Andrewartha dan Birch (1954) bahwa faktor-faktor yang mempengaruhi pertumbuhan, perkembangan, dan kerapatan populasi adalah tersedianya sumberdaya seperti makanan dan ruang tempat hidup serta aksesibilitas sumberdaya dan kemampuan individu-individu populasi untuk mencapai dan memperoleh sumberdaya (antara lain sifat penyebaran, pemencaran dan kemampuan mencari). Limbah yang makin kering menyebabkan pupa berkembang kurang optimal. Susanto (2011) mengemukakan bahwa larva dan pupa dapat berkembang dengan sempurna apabila suhu berkisar $27^{\circ} \mathrm{C}-$ $29^{\circ} \mathrm{C}$. Pada saat musim penghujan, suhu tanah relatif lebih tinggi dan berada pada rentang suhu optimum yang dibutuhkan larva dan pupa kumbang badak, sehingga jumlah larva dan pupa pada saat musim penghujan relatif lebih banyak. Pada suhu optimum, kemampuan perkembangan tiap stadium serangga baik dan mortalitas sebelum batas umur akan sedikit (Jumar, 2000). Menurut Siahaya (2014), kelembaban habitat yang optimum bagi stadium larva dan pupa adalah $85 \%-95 \%$, sedangkan imago berkisar $80 \%$. Kelebihan kelembaban, terutama pada stadium larva dan pupa dapat mempermudah jamur tumbuh yang dapat menghambat perkembangan larva dan pupa sehingga meningkatkan mortalitas. Pada saat musim kemarau sampling pertama dan kedua kelembaban kurang dari $85 \%$, sehingga jumlah pupa saat musim kemarau jumlahnya lebih kecil dibanding musim penghujan. Menurut Kumar et al. (2007), suhu dan kelembaban berpengaruh pada perkembangan kumbang badak.

Menurut Rajan et al. (2010), limbah organik yang telah terdekomposisi menjadi kompos, kotoran ternak, serta batang pohon kelapa membusuk menjadi tempat yang disukai kumbang badak untuk bertelur. Jenis makanan, kandungan air dalam makanan dan besarnya butiran material juga berpengaruh terhadap perkembangan suatu jenis serangga hama (Jumar, 2000). Menurut Setyorini et al. (2006) pada umumnya limbah bahan organik mempunyai perbandingan Karbon terhadap Nitrogen $(\mathrm{C} / \mathrm{N})$ yang tinggi, misalnya jerami $50-70$, dedaunan tanaman 50-60, kayu-kayuan $>400$, dan lain-lain. Hal tersebut sejalan dengan Marhaeni (2008) yang mengemukakan bahwa limbah membantu penyebaran OPT secara pasif. Menurut Yustina et al (2012) sampah yang membusuk dan tandan kosong sawit yang tersisa setelah pemanenan dan daun-daun yang telah membusuk, kondisi seperti ini merupakan tempat yang sangat cocok untuk kumbang badak berkembang.

Temperatur habitat yang cocok bagi perkembangan pupa adalah $27^{\circ} \mathrm{C}-$ $29^{\circ} \mathrm{C}$. Bila temperatur habitat cocok, maka perkembangan pupa dalam kokon menjadi optimal. Sebagaimana dikemukakan oleh Siahaan (2013) bahwa temperatur yang tinggi dapat memperlambat perkembangan pupa. Pupa berada dalam kokon yang dibuat dari bahan organik di sekitar tempat hidupnya (Prawirosukarto, 2003). Menurut Siahaan (2013) musim kemarau panjang, suhu tinggi, dan jumlah makanan yang sedikit memperlambat perkembangan 
larva dan pupa serta menyebabkan ukuran stadium imago lebih kecil.

Limbah dengan nilai probabilitas terkecil sebesar $\quad 0,000 \quad(P<0,20)$ memberikan pengaruh sangat nyata dan menjadi faktor ekologis yang paling berpengaruh terhadap struktur populasi kumbang badak. Hal ini dikarenakan limbah merupakan habitat bagi larva kumbang badak. Edward (2011) mengemukakan bahwa keterbatasan nutrisi dari limbah merupakan bentuk daya dukung lingkungan yang mulai berkurang. Limbah paling berpengaruh terhadap perkembangan kumbang badak, untuk itu perlu adanya sanitasi lingkungan. Serasah daun yang menumpuk di kebun sebaiknya dibersihkan secara rutin. Batang kelapa yang tidak dipakai sebaiknya diperiksa tumpukannya secara berkala. Selain itu, batang pohon kelapa yang mati terkena petir atau akibat lain sebaiknya segera ditebang. Hal ini dikarenakan batang pohon mati yang tidak langsung ditebang juga dapat dijadikan sarang larva kumbang badak untuk berkembang. Sebagaimana dikemukakan Moore et al. (2015) bahwa pohon kelapa yang dibiarkan tetap berdiri setelah mati dan tandan bunga kelapa dapat menjadi tempat kumbang badak berkembang biak. Jerami padi sebagai preferensi lokasi dipilih sebenarnya dapat dimanfaatkan kembali, untuk dijadikan pakan ternak.

Pada gambar 4.2 dapat diketahui bahwa larva tumbuh dengan cepat sampai pada titik stasionernya pada nilai 1,75 kemudian turun. Persamaan untuk kurva tersebut adalah $y=2,159-1,109 x^{2}$. 0,599x-0,093 (lihat tabel 4.3). Limbah menjadi faktor pembatas populasi bagi kumbang badak di Kutasari. Menurut Rohmani (2013), bagi organisme dengan kisaran toleransi yang lebar (eury) terhadap faktor abiotik yang relatif konstan bukan merupakan faktor pembatas, sehingga organisme tersebut dapat hadir dalam jumlah banyak. Sebaliknya, bagi organisme dengan
Jerami setelah panen dapat dibersihkan dan diproses fermentasi untuk jadikan pakan ternak. Jerami mengandung sumber karbon yang baik. Pentingnya penghancuran habitat yang menjadi situs perkembangan juga dikemukakan oleh Soltani (2010) yang mengemukakan bahwa penghancuran situs yang menjadi tempat perkembangan kumbang badak dapat mengurangi populasi kumbang badak.

Pengaruh limbah terhadap kelimpahan stadium larva dapat disusun dalam kurva estimasi sebagai berikut :

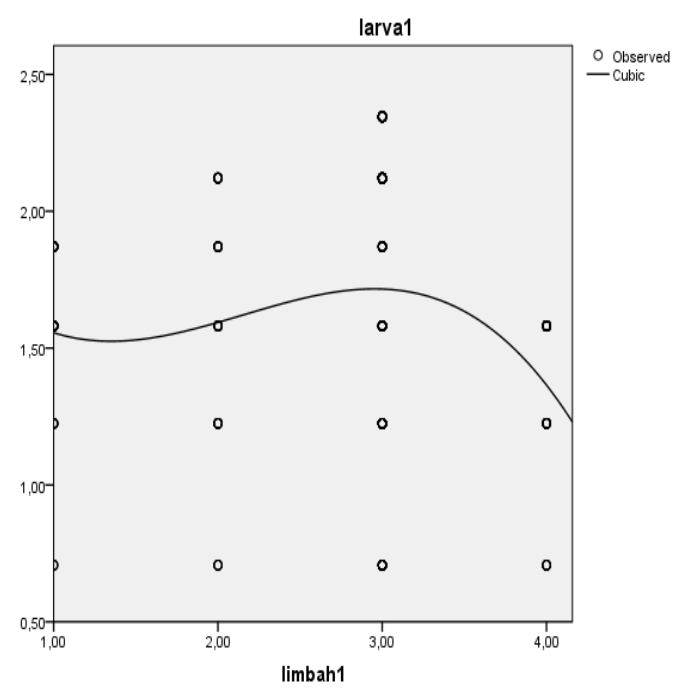

Gambar 4.2. Kurva Estimasi Pertumbuhan Larva

toleransi yang sempit (steno) terhadap faktor abiotik yang selalu berubah akan menjadi faktor pembatas sehingga akan hadir dalam jumlah sedikit.

Kelimpahan masing-masing stadium selanjutnya disusun dalam piramida yang dibedakan per musim. Saat musim kemarau jumlah imago (individu tua) paling banyak yaitu $2,4 \pm 0,8$, disusul kemudian pupa $1,53 \pm 0,5$, dan jumlah terkecil adalah larva dengan $1,35 \pm 0,7$. Piramida yang disusun dari data tersebut adalah piramida terbalik (gambar 4.3) yang berarti populasi hampir punah. 
Tabel 4.3.Model Persamaan Kurva Estimasi

Dependent Variable:Iarva1

\begin{tabular}{|l|r|c|c|c|c|c|c|c|c|}
\hline \multirow{2}{*}{ Equation } & \multicolumn{4}{|c|}{ Model Summary } & \multicolumn{4}{c|}{ Parameter Estimates } \\
\cline { 2 - 10 } & R Square & $F$ & df1 & df2 & Sig. & Constant & b1 & b2 & b3 \\
\hline dimension1 Cubic &, 066 & 8,375 & 3 & 356 &, 000 & 2,159 & $-1,109$ &, 599 &,- 093 \\
\hline
\end{tabular}

The independent variable is limbah1.

\begin{abstract}
Kelimpahan masing-masing
stadium selanjutnya disusun dalam piramida yang dibedakan per musim. Saat musim kemarau jumlah imago (individu tua) paling banyak yaitu $2,4 \pm 0,8$, disusul kemudian pupa $1,53 \pm 0,5$, dan jumlah terkecil adalah larva dengan $1,35 \pm 0,7$. Piramida yang disusun dari data tersebut adalah piramida terbalik (gambar 4.3) yang berarti populasi hampir punah.
\end{abstract}

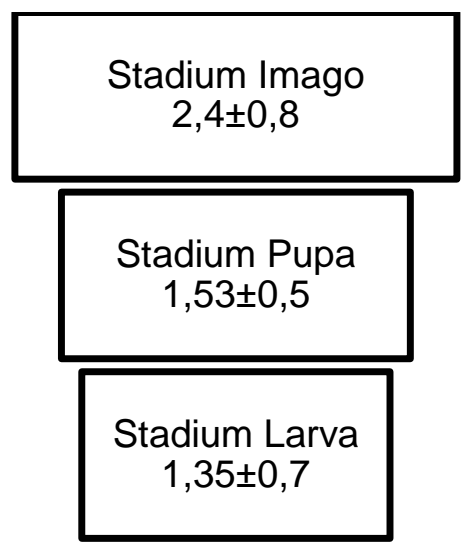

Gambar 4.3. Piramida Umur Struktur Populasi Kumbang Badak Musim Kemarau

\section{Kesimpulan dan Saran}

Berdasarkan hasil penelitian yang telah dilakukan mengenai faktor ekologis yang berpengaruh terhadap struktur populasi kumbang badak dapat disimpulkan sebagai berikut:

1. Kelimpahan masing-masing stadium kumbang badak pada musim kemarau menghasilkan piramida terbalik sedangkan pada musim penghujan menghasilkan piramida seimbang.

2. Faktor-faktor ekologis yang berpengaruh pada struktur populasi
Pertumbuhan melambat kemudian berhenti ketika sumber daya nutrisi habis (pertumbuhan logistik). Namun pada musim penghujan, jumlah larva mengalami peningkatan menjadi $3,5 \pm 1$, kemudian terbanyak kedua adalah imago yaitu $3,2 \pm 1,0$ dan yang terkecil adalah pupa dengan $1,7 \pm 0,7$. Berdasarkan data, maka bentuk piramida dengan jumlah individu tua dan muda hampir sama adalah bentuk piramida seimbang (gambar 4.4).

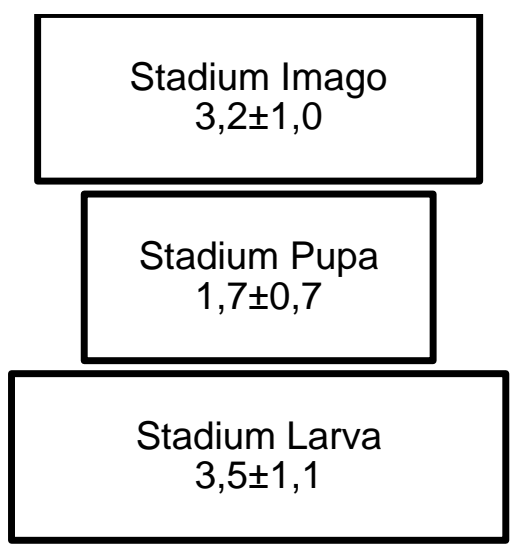

Gambar 4.4. Piramida Umur Struktur Populasi Kumbang Badak Musim Penghujan.

kumbang badak adalah limbah material organik berpengaruh hanya pada stadium larva sedangkan suhu dan kelembaban habitat berpengaruh hanya pada stadium pupa.

3. Faktor yang paling bepengaruh adalah limbah material organik karena memiliki nilai probabilitas terkecil.

4. Habitat yang paling disukai larva kumbang badak adalah limbah serasah daun karena mengandung zat-zat yang dibutuhkan larva untuk berkembang. 


\section{Daftar Pustaka}

Abidin,

C.M.R.Z,

A.H.Ahmad,

H.Salim.and N.H.Hamid. 2014.

Population Dynamics of Oryctes rhinoceros in Decomposing Oil Palm Trunks in Areas Practising Zero Burning and Partial Burning. Journal of Oil Palm Research 26 (2) : 140-145

Andrewartha,H.G., and L.C.Birch, 1954. The Distribution and Abundance of Animals. The University of Chicago Press.Chicago

Ayuningtyas, D.N. 2009. Pengaruh Sistem Aerasi Dan Ketersediaan OksigenTerhadap Laju Proses Pengomposan Dan Kualitas Kompos Berbahan Baku Limbah Pencucian Biji Kakao Terfermentasi, Serasah Daun Dan Kotoran Sapi.DepartemenTeknik Pertanian Fakultas Teknologi Pertanian, Institut Pertanian Bogor.

Badan Pusat Statistik kabupaten Purbalingga. 2014. Kutasari dalam Angka. BadanPusat Statistik Kabupaten Purbalingga. Purbalingga.

Balitka, 1989. Pengendalian kumbang Kelapa secara Terpadu. Badan litbang,

Balika, FAO/UNDP, Dirjenbun, Direktorat Perlintan. 29 pp

Capinera, J.L. 2012. Sweetpotato Weevil, Cylas formicarius (Fabricius) (Insecta: Coleoptera: Brentidae

(Curculionidae)).https://edis.ifas.ufl .edu/in154 capinera spw1.

Edwards, W. J. \& Edwards, C. T. 2011. Population Limiting Factors. Nature Education Knowledge 3(10):1-4

Giblin-Davis, R. M. 2001. Borers of Palms. In F. W. Howard, D. Moore, R. M. Giblin-Davis, and R.

G. Abad [eds.] Insects on Palms. CABI Publishing. pp. 267-304.

Jumar. 2000. Entomologi Serangga. PT. Rineka Cipta, Jakarta

Kalshoven, L.G.E. 1981. The Pest of Crop In Indonesia. P.A. Van Der Laan. PT.

IchtiarBaru-Van Hoeve.Jakarta.

Kamarudin, N, MB Wahid, and R Moslim. 2005. Environmental Factors Affecting The Population Density Of Oryctes rhinoceros In A Zero-Burn Oil Palm Replant.Journal of Oil Palm Research (17) 53-63

Kasmiran,A. 2011. Pengaruh Lama Fermentasi Jerami Padi dengan Mikroorganisme Lokal terhadap Kandungan Bahan Kering, Bahan Organik, Dan Abu. Lentera 11(1)48-52

Kumar, S., \& Ahmad, M. 2007. Effect of temperature and humidity on biology of rhinoceros beetle, Oryctes rhinoceros Linn. on oil palm. Journal of Applied Zoological Researches, 18(2), 108-112.

Loring, D.A. 2007. Competitive Testing of SLPLAT-RB (Oryctes rhinoceros L.) Male Aggregation PeromoneMass Trapping In Oil Palm And Coconut

Estates. The Planter. (979): 657663.

Marhaeni, L.S., 2008. Inventarisasi Hama dan Penyakit Penting pada Tanaman Kelapa.Perspektif 7(2) : 112-117

Martawidjaja, M. 2003. Pemanfaatan Jerami Padi sebagai Rumput 
untuk Ternak Ruminansia Kecil. Wartazoa 13 (3):119-127

Moore, $\mathrm{A}, \mathrm{T}$ Jackson, $\mathrm{R}$ Quitugua, $\mathrm{P}$ Bassler, and R Campbell. 2015. Florida Entomologist 98(3):10121014.

Olowu, R.A., B.A. Moronkola, O.O. Tovide, AA, Denloye, K.N. Awokoya, C.E. Sunday and. O.O. Olujimi .20012.Assesment of Proximate and Mineral Status of Rhinoceros beetle Larva, Oryctes rhinoceros Linnaeus (1758) (Coleoptera:Scarabaeidae) from Itokin, Lagos State, Nigeria. Research Journal of Environmental Science 6 (3): 118124

Omotoso, OT. 2015. Nutrient Composition, Mineral Analysis and Anti-nutrient Factors of Oryctes rhinoceros L. (Scarabaeidae: Coleoptera) and Winged Termites, Marcrotermes nigeriensis Sjostedt. (Termitidae: Isoptera).British Journal of Applied Science \& Technology 8(1): 97-106

Pracaya, 2009. Hama Dan Penyakit Tanaman. Penebar Swadaya. Jakarta

Prihartini, I, Soebarinoto, S Chuzaemi dan M Winugroho. 2008. Karakteristik Nutrisi dan Degradasi Jerami Padi Fermentasi oleh Inokulum Lignolitik TLiD dan BopR. Animal Production 11 (1) 1-7

Rajan,P., C. Mohan and A. Josephrajkumar.2010. Integrated pest management in coconut. Proceedings of International Conference on Coconut Biodiversity for Prosperity. October 25-28, 2010. Kerala p.326

Rahayuwati, S., R. D de Chenon dan Sudharto ps. 2002. sistem Reproduksi Betina Oryctes rhinoceros (Coleoptera:Scarabaeidae) dari
Berbagai Populasi Berbeda di Perkebunan Kelapa sawit. Jurnal Penelitian Kelapa Sawit. 10(1):1122.

Riostone, U,. 2010. How Reaction Pesticide for pest in chicago. Clempsonuniversity. South Carolina.

Rohmani, Y.D. 2013. Faktor Pembatas. Jurnal Faktor Pembatas(2)1:1-6

Satianto,E. 2008, Pencampran Serbuk Penggergajian Batang Kelapa dengan Termoplastik Propilena Untuk Bahan Kemasan Jerigen Plastik. Tesis Sekolah Pasca Sarjana USU,Medan

Siahaan, IRT dan Syahnen. 2013. Mengapa $O$. rhinoceros menjadi Hama pada Tanaman Kelapa Sawit?. Laboratorium Lapangan Balai Besar Perbenihan dan Proteksi Tanaman Perkebunan (BBPPTP) Medan

Siahaya, VG. 2014. Tingkat Kerusakan Tanaman Kelapa oleh Serangan Sexava nubila dan Oryctes rhinoceros di Kecamatan Kairatu, Kabupaten Seram Barat. Jurnal Budidaya Pertanian 10(2): 93-99

Soltani, R. 2010. The Rhinoceros Beetle Oryctes agamemnon arabicus in Tunisia: Current Challenge and Future Management Perspectives.Tunisian Journal of Plant Protection 5 (2) :179-194

Sudarsono, H. 2008. Pengaruh Lama Periode Kering dan Intensitas Curah Hujan terhadap Penetasan Belalang Kembara (Locusta migratoria manilensis Meyen).J. HPT Tropika. 8(2): $117-122$

Supriyadi, S. 2008. Kandungan Bahan Organik sebagai Dasar Pengelolaan Tanah di Lahan Kering Madura. Embryo 5(2):176183. 
Susanto, A, Sudharto, dan AE Prasetyo. 2011. Informasi Organisme Pengganggu Tanaman Kumbang Tanduk Oryctes rhinoceros Linn. Artikel. Pusat Penelitian Kelapa Sawit: Medan.

Wesi, Jasmi., dan A. Lusi. 2014. Kepadatan Populasi Kumbang Tanduk (Oryctes rhinoceros L.) pada Tanaman Kelapa Sawit di PTPN VI Unit Usaha Ophir Pasaman Barat. Jurnal Penelitian Kelapa Sawit, 15 (2) : 69-82
Yulianto, Y dan A Kanthi. 2013. Analisis Fluktuatif Serangan Hama Oryctes rhinocheros L Pada Tanaman Kelapa di Wilayah Propinsi Jawa Timur Pada Bulan Agustus 2013. BBPPTP Surabaya.

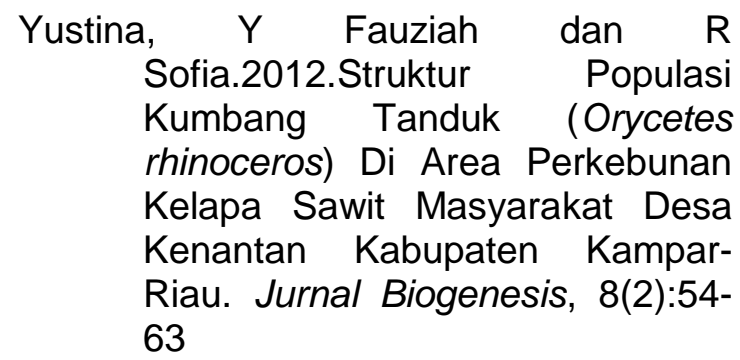

